\title{
ANALISE SENSORIAL DA BEBIDA DO CAFÉ CONILON DE CLONES DE MATURAÇÃO PRECOCE
}

\author{
Antônio Drumond Neto ${ }^{1}$ \\ Gustavo Soares de Souza ${ }^{2}$ \\ Sergio Henriques Saraiva ${ }^{3}$ \\ Samuel de Assis Silva ${ }^{4}$ \\ Julião Soares de Souza Lima ${ }^{5}$
}

Resumo: Este trabalho foi desenvolvido com os cinco clones de maturação precoce do conilon Vitoria, em uma área comercial, em altitude de $520 \mathrm{~m}$. Em três talhões coletou-se café cereja para cada clone e processou-se amostra em fruto natural (coco) e desmucilado. As amostras foram secas inicialmente em terreiro suspenso por $24 \mathrm{~h}$ e depois em estufa a 45 graus até obter teor de água de $12 \%$ bu. $A$ análise sensorial, da prova de xicara, foi realizada por três degustadores. Os valores obtidos foram analisados pela ANOVA e quando significativos utilizou-se o teste de Tukey para o contraste entre as médias da característica bebida $(p<0,05)$. A bebida apresentou diferença significativa com relação ao processamento das amostras com média de 82,77 para desmucilado e 80,93 para o natural. O processamento dos frutos e os clones não apresentam interação. O clone que apresentou maior valor médio da bebida foi o número 4 , com valor de 84,58 pontos.

Palavras-chave: Café de qualidade; Altitude; Café desmucilado.

\footnotetext{
${ }^{1}$ Agronomia/Universidade Federal do Espírito Santo, Brasil. E-mail: agrodrumond@gmail.com.

2 Agronomia/Instituto Capixaba de Pesquisa, Assistência Técnica e Extensão Rural, Brasil. E-mail: gsdsouza@hotmail.com.

${ }^{3}$ Engenheiro de Alimentos/Universidade Federal do Espírito Santo, Brasil. E-mail: sergiohsaraiva@gmail.com.

${ }^{4}$ Agronomia/Universidade Federal do Espírito Santo, Brasil. E-mail: samuel.assilva@gmail.com.

${ }^{5}$ Engenheiro Agrícola/Universidade Federal do Espírito Santo, Brasil. E-mail: limajss@yahoo.com.br.
} 